\title{
Miradas cómplices: cine etnográfico, estrategias colaborativas y antropología visual aplicada
}

\section{Looks of complicity: Ethnographic cinema, collaborative strategies, and applied visual anthropology}

\author{
Antonio Zirión Pérez \\ Departamento de Antropología, Universidad Autónoma Metropolitana-Iztapalapa, \\ Ciudad de México, México \\ ORCID: https://orcid.org/o0o0-0002-6I43-8079 \\ ISSN: ISSN-OI85-4259; e-ISSN: 2007-9I76 \\ DoI: http://dx.doi.org/I0.28928/revistaiztapalapa/782015/atc2/zirionpereza
}

\section{Resumen}

Este artículo sistematiza las bases, delinea los contornos y atisba los alcances de un fértil método de producción audiovisual e investigación etnográfica. Se argumenta que el documental colaborativo, anclado en la vieja tradición del cine etnográfico y estrechamente emparentado con la joven disciplina de la antropología visual, permite vislumbrar nuevos horizontes para la teoría y la práctica antropológica, y plantea la posibilidad de una antropología visual aplicada. En los últimos años, debido a la revolución de la imagen digital, las estrategias colaborativas en la producción audiovisual constituyen cada vez más una plataforma viable para el diálogo intercultural.

Palabras clave: etnografía, documental, colaboración, cine intercultural, redes audiovisuales

\footnotetext{
Abstract

This article attempts to systematize the bases, outline the contours and glimpse the scope of a fertile research method within contemporary ethnography. I intend to argue that collaborative documentary, anchored in the old tradition of ethnographic film and closely related to the young discipline of visual anthropology, foresees new horizons for anthropological theory and practice, based on the idea of an applied visual anthropology. In recent years, due to the digital image revolution, these collaborative strategies in audiovisual production increasingly constitute a reliable platform for intercultural dialogue.

Keywords: Ethnography, Documentary, Collaboration, Transcultural Cinema, Audiovisual Networks.
}

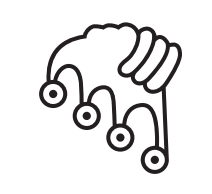

\section{IZTAPALAPA}

Agua sobre lajas

\footnotetext{
Doctor en Ciencias Antropológicas. Sus principales líneas de investigación son antropología visual y cultura urbana. zirion@xanum.uam.mx
} 

ste artículo intenta sistematizar las bases, delinear los contornos y atisbar los alcances del cine documental colaborativo, un campo anclado en la vieja tradición del cine etnográfico y estrechamente emparentado con la joven disciplina de la antropología visual, pero que a su vez trasciende las fronteras disciplinares y permite vislumbrar nuevos horizontes para la teoría y la práctica antropológica. En los últimos años, debido a la revolución de la imagen digital, estas estrategias colaborativas en la producción audiovisual constituyen cada vez más una plataforma promisoria para el diálogo intercultural.

Primero se procede a repensar la antropología visual, a desvanecer prejuicios y refocalizar sus alcances, sus límites y su potencial no solo para la antropología, sino para otras ciencias sociales y humanidades. Después se revisan los criterios que podemos utilizar para identificar y estimar el valor antropológico o etnográfico de una imagen. Luego se ensaya una caracterización del cine etnográfico y sus elementos constitutivos: observación, participación, escucha y diálogo. A partir de esto el artículo se centra en la especificidad del documental colaborativo, abordando cuestiones como su misma denominación, su significado y sus diversas modalidades, así como sus bases filosóficas. También se hace un breve recuento de los orígenes e hitos que han marcado el desarrollo del cine colaborativo a nivel mundial y particularmente en el cine mexicano, desde los principales precursores hasta el boom que atraviesa en la actualidad. En la era de la llamada "convergencia digital" se amplifica el potencial que tiene la imagen para fungir como una plataforma de comunicación intercultural.

Es importante señalar desde un inicio que este texto no busca más que esbozar un panorama general de varias ideas y múltiples temas pertinentes para comprender el cine colaborativo; no pretende discutir a profundidad casos específicos, ni ahondar en todos sus matices y sutilezas. Esta elección de un enfoque amplio y general, en vez de uno más minucioso y detallado, responde a dos circunstancias. Por un lado, a que, a diferencia de la academia anglohablante, donde la genealogía del documental colaborativo es bastante más conocida, en los ámbitos latinoamericanos aún carecemos de un recuento sistemático de este género; por ello me parece no solo pertinente sino urgente exponer, primero que nada, un estado de la cuestión. Por otro lado, dada 
la naturaleza transdisciplinaria del tema, en vez de tratar cuestiones conceptuales muy específicas, este texto aspira a despertar el interés y abrir el horizonte de la etnografía colaborativa para un lector proveniente de distintas disciplinas, desde el cine, las artes visuales, la antropología, las humanidades, las ciencias sociales o los estudios culturales. Por esto mismo hemos optado por un estilo ensayístico, usando, en la medida de lo posible, términos coloquiales, y evitando a toda costa recurrir a un lenguaje demasiado técnico o especializado.

\section{Refocalizando la antropología visual}

Quisiera discutir cuatro mitos muy generalizados acerca de la antropología visual, que a mi juicio han obstaculizado su desarrollo dentro de las instituciones académicas en México y en otros países latinoamericanos.

I) Existe una falsa idea de que representa una forma innovadora de hacer investigación, surgida en años recientes gracias a las nuevas tecnologías de la imagen digital. Si bien como disciplina académica es relativamente joven (hace apenas unos 25030 años que se formaron los primeros centros de investigación, producción y formación en antropología visual, principalmente en universidades británicas, francesas y estadounidenses), en tanto práctica, en realidad se remonta al nacimiento mismo de la fotografía y el cine a finales del siglo xix, y su desarrollo a partir de ese momento correría paralelo con la trayectoria de la antropología como disciplina científica. El cine etnográfico y la fotografía antropológica tienen más de roo años de existencia; no podemos ignorar las lecciones de un siglo entero de experiencias; resulta fundamental conocer su historia y estudiar a fondo la obra de los precursores en esta materia, para aprender de sus errores y sus logros, y entender mejor en dónde estamos parados. Pensar en la antropología visual como una disciplina novedosa es un error que no ha favorecido en nada su comprensión.

2) Otra opinión común es que la antropología visual es una forma de antropología light, que pierde el rigor conceptual y la profundidad de análisis que posee la antropología escrita. Este prejuicio está basado en la creencia de que la antropología visual puede prescindir de la palabra. A nuestro entender, el uso de la imagen en la antropología debe siempre conjugarse con la antropología verbal. La antropología visual no constituye un refugio ni una alternativa fácil para aquellos estudiantes de antropología a quienes no les guste leer ni escribir. La integración de los medios audiovisuales a la investigación antropológica no excusa a los antropólogos de pensar, debatir y comunicar por escrito o en forma oral las experiencias y los conocimientos 
generados. Lo visual y lo verbal no son simplemente formas distintas de comunicar lo mismo, son lenguajes que comunican diferente tipo de información, que bien articulados pueden apuntar en un mismo sentido y reforzar, cada uno a su manera, la tesis central de una investigación. Palabra e imagen constituyen dos caminos paralelos e independientes pero a la vez complementarios para la investigación antropológica, son dos formas igualmente válidas de apelar a la inteligencia y la sensibilidad humanas. Más que usarlas una en función de la otra (como imágenes que ilustran textos o como textos que explican imágenes), lo ideal es que se alimenten y enriquezcan recíprocamente.

3) No nos resulta muy adecuado concebirla como una subdisciplina, sino más bien como una especialidad que resalta y refuerza el carácter transdisciplinario de la antropología. En lugar de considerarla una pequeña ramificación parece más apropiado asumirla como un afluente encauzado hacia otras áreas del conocimiento, y que la acerca más a las humanidades y a las artes. Al establecer un diálogo con el mundo de la imagen, la antropología se perfila como una disciplina acaso más libre y abierta, marcadamente cualitativa y creativa, alejada de estadísticas, cuestionarios, entrevistas formales y estudios cuantitativos, propios de una vocación cientificista. Esta perspectiva permite trascender las fronteras tradicionales entre la antropología académica y otras esferas de la producción cultural y la expresión artística.

4) Al contrario de lo que suele pensarse, la antropología visual no es una simple técnica de registro. Ciertamente, la cámara puede usarse como una herramienta que implica el desarrollo de una técnica particular y puede incluso llegar a emplearse sistemáticamente como una metodología etnográfica. Pero la imagen no es únicamente un instrumento para la documentación etnográfica, sino un auténtico vehículo de conocimiento; representa una forma distinta de observar, de abordar y analizar la cultura y la sociedad. Además, el auge de los estudios sobre cultura visual, sobre la representación y los imaginarios en distintas culturas y sociedades, es prueba suficiente de que la antropología visual ha construido también una consistente base teórica y se ha convertido en un campo de discusión muy activo y sugerente. Por ello, deberíamos entenderla como un paradigma alternativo o un modo diferente de producción del conocimiento antropológico.

\section{Contornos difusos}

Sin duda puede ser cuestionable la pertinencia, la exactitud o la vigencia del término "antropología visual", propuesto originalmente por Margaret Mead durante los años 
cuarenta, a propósito de su trabajo de campo en Bali, junto con Gregory Bateson, en el que empleaban la foto y el cine para documentar el temperamento y los comportamientos balineses (Jacknis, I988:165). En primer lugar, ¿̨no es redundante decir "antropología visual", cuando en sentido estricto no hay ninguna antropología que no sea de algún modo visual? La observación siempre se ha considerado un componente crucial e ineludible de la investigación antropológica; sería difícil imaginar una antropología no-visual, ciega, una etnografía que prescindiera completamente del sentido de la vista. No obstante, el tema de la mirada rara vez ha sido abordado frontalmente por los antropólogos, casi siempre se da por sentada o aparece solo de manera tangencial. A nuestro entender, el nombre surge frente a la predominancia de lo oral y de la palabra escrita dentro de la disciplina, para distinguir a una antropología que se preocupa de manera central por la cuestión de la mirada, la observación y la representación visual de las culturas. Así, el término visual, aunque pudiera parecer redundante, se ha mantenido como una estrategia de resistencia, como una bandera frente a la renuencia de los sectores más conservadores de la academia a admitir la imagen como una vía válida para el ejercicio de la antropología.

El término "visual" a veces parece salir sobrando y otras veces resulta insuficiente. Llega a ser apropiado cuando se habla de foto fija, de pintura, grabado o dibujo. No obstante, resulta demasiado estrecho cuando hablamos de cine o video, que incorporan la dimensión sonora, por lo que quizás sería más correcto hablar de antropología "audiovisual", como hacen ya varios teóricos de habla hispana, o quizás sería todavía más adecuado hablar de una antropología “multimedia”. En los últimos años se ha gestado un importante giro conceptual dentro de la antropología visual, que se propone ir más allá de la imagen para explorar otros sentidos a través de diferentes medios, planteando así la posibilidad de una antropología "multisensorial" y "transmediática".

De acuerdo con la definición de antropología que propone Esteban Krotz (1994:8), no por su objeto de estudio sino por el interrogante que se plantea acerca de la identidad y la alteridad dentro del universo de lo humano, podríamos entender la antropología visual de manera muy simple, como el planteamiento de la pregunta antropológica en términos audiovisuales, es decir, a partir de o a través de la imagen; utilizando la imagen como recurso de investigación, medio para la transmisión de experiencias etnográficas y generación de conocimiento antropológico. Podría decirse que la esencia de la antropología visual se manifiesta claramente cuando una imagen nos suscita, intencional o involuntariamente, interés, empatía, curiosidad, asombro o extrañamiento ante la otredad y la diversidad sociocultural. 
Para apreciar la importancia de la antropología visual es importante dejar de verla como una moda o una corriente pasajera en la práctica etnográfica contemporánea, ligada a las tecnologías del momento. Sobre todo es fundamental insistir en que, lejos de ser una mera herramienta, plantea, en mi opinión, un cambio de paradigma significativo dentro del pensamiento antropológico. Genera una doble revolución: por una parte, un cuestionamiento profundo de la antropología misma, de la concepciones tradicionales sobre su naturaleza, sus propósitos y sus estrategias; y por otra parte conduce a un replanteamiento radical de la manera en que se ha abordado la imagen desde otras disciplinas, como las artes visuales, la comunicación, la estética, la psicología, la historia del arte. La especificidad o lo distintivo de la antropología de la imagen es que la entiende a través de su valor simbólico y a partir de su estrecho vínculo con la cultura y las dinámicas sociales, o bien la utiliza como un instrumento de diálogo transcultural.

\section{El valor antropológico de una imagen}

¿Dónde radica el valor etnográfico de una imagen? ¿Qué le otorga relevancia desde el punto de vista antropológico? ¿A qué nos referimos cuando decimos que una película o una fotografía son antropológicas? De entrada y en sentido amplio, podemos considerar de interés para la antropología todos aquellos materiales audiovisuales, sin importar el formato, el soporte, la duración, o si es documental, ficción, videoarte, instalación o performance (desde los códices del siglo xvi, los grabados del siglo XIX, las películas y telenovelas, el grafiti y los tatuajes, la imagen digital y las nuevas plataformas multimedia) que nos remitan de alguna manera a un encuentro con la otredad, que nos provoque, directa o indirectamente, la inquietud fundamental que da origen a la experiencia etnográfica, que despierte nuestra mirada e imaginación antropológica. Sin embargo, con un criterio tan amplio se corre el riesgo de caer en un relativismo radical en el que todo se vale y cualquier imagen puede entonces ser considerada etnográfica o antropológica. Definitivamente, es necesario afinar un poco más los parámetros.

Para ello podemos echar mano de cuatro criterios bastante útiles: 1) El objeto de la imagen (si coincide con los temas clásicos de la antropología, por ejemplo, los pueblos indígenas). 2) La metodología empleada (su forma de aproximarse a los sujetos, si es mediante la observación cercana y la participación directa).3) La interpretación (lo antropológico no reside en la imagen en sí misma, sino en la mirada, tanto de quien la produce como de quienes la reciben, y en la interpretación 
que de ella se haga).4) La apelación a la autoridad y la legitimidad académica (si la imagen fue realizada o analizada por un antropólogo profesional, o si es parte de un proyecto formal de investigación avalado por alguna institución académica). Este último me parece el criterio más engañoso (aunque se recurre muy comúnmente a él) porque irónicamente las mejores películas etnográficas y las mejores fotografías antropológicas no han sido realizadas por antropólogos que se acerquen al lenguaje audiovisual, sino por cineastas o fotógrafos profesionales que poseen cierta sensibilidad e imaginación antropológica.

En última instancia, todos estos criterios pueden llegar a ser pertinentes en algunos casos, pero ninguno de ellos es suficiente para determinar definitivamente el valor o el carácter antropológico de una imagen. Además, tampoco se trata simplemente de determinar si una foto o una película poseen o no carácter antropológico; no es una cuestión de todo o nada, sino que hay toda una gama de grados y matices a considerar. Así, la antropología visual está condenada a formularse en forma recurrente las preguntas mencionadas arriba, como una interrogación constante, imposible de resolver de manera definitiva, pero que necesariamente tiene que plantearse caso por caso, ante cualquier expresión o representación audiovisual de fenómenos socioculturales o de cualquier dimensión de la existencia humana.

Por otro lado, resulta incuestionable la importancia que puede tener la imagen para la antropología en tanto instrumento para la investigación etnográfica. Al igual que la palabra, pero de distintos modos, la imagen describe, encierra y transmite información, ideas y significados. Las fotos y los videos pueden servir como recordatorio, como auxiliares de la memoria y detonadores de ideas y reflexiones para el investigador. Las imágenes y la cultura visual representan una fuente inagotable de investigación, constituyen una alternativa legítima para comunicar experiencias etnográficas y generar nuevas formas de conocimiento antropológico.

\section{Cine etnográfico}

Hablar de cine etnográfico en la actualidad puede abarcar una amplia variedad de géneros y tipos de películas: desde el registro audiovisual con fines meramente académicos, pasando por la creación documental que emplea técnicas de investigación etnográfica, hasta cintas de ficción que abordan aspectos de interés para la antropología. El cine etnográfico poco a poco se ha consolidado como un género dentro de los circuitos contemporáneos. En sus nuevas tendencias se diluyen las fronteras tradicionales entre la ficción y el documental, y adopta sin reservas una 
rica variedad de recursos y estilos de representación tanto del documental clásico expositivo, el cine directo, el video-diario, las narrativas autorreflexivas, los ensayos fílmicos experimentales o las etnoficciones más vanguardistas.

Entonces, ¿̇cómo podemos entender este cine etnográfico?, ¿por qué es importante reconocerlo, estudiarlo y practicarlo? Distintos teóricos tienden a coincidir en que se trata de un género que captura y reproduce rasgos y características de personas pertenecientes a una cultura o grupo social, y los ofrece a gente de otras culturas o grupos sociales. Pero más que buscar definiciones y preguntarnos qué es exactamente, quizá sería más productivo averiguar en qué casos, bajo qué parámetros y en qué sentidos podemos decir si una película debe considerarse "cine etnográfico". Nuevamente, existen distintos criterios para establecer el carácter antropológico de un filme, unos más estrictos que otros. Algunos autores lo asumen como una actividad puramente científica, que sirve para la consulta e investigación especializada, para la formación profesional de los antropólogos, o para la divulgación del conocimiento y la educación del público general. Otros no tienen problema en llamar antropológicas a películas producidas sin pretensiones académicas, pero que resultan de valor e interés etnográfico, ya sean documentales o de ficción.

Estas ideas ponen de manifiesto la dificultad e inutilidad de elaborar una caracterización total y definitiva de lo que es el cine etnográfico. Otra pregunta que se suele plantear es por qué llamarlo cine "etnográfico" y no "antropológico", y si habría alguna diferencia. Sin duda un antropólogo puede fácilmente discernir los matices entre uno y otro término, y en función de ello distinguir entre un cine más etnográfico (práctico) y otro de carácter más bien antropológico (teórico). Pero de hecho, al clasificar los géneros y subgéneros ya se ha vuelto una convención el uso de la etiqueta de "cine etnográfico". Sin preocuparnos demasiado por esta cuestión terminológica, en este escrito se adopta el nombre de "cine etnográfico" sin mayores reservas, aunque también se usa el adjetivo "antropológico", que muchas veces resulta igualmente adecuado.

De acuerdo con los criterios ya esbozados más arriba, la naturaleza antropológica de una película no se encuentra tan solo en el objeto o los sujetos representados ni únicamente en el producto final, sino que reside sobre todo en el proceso de acercamiento e interacción con los sujetos; es decir, nace de un encuentro y una empatía genuina entre distintas culturas. También considero que una película no es antropológica por sí sola, sino que este calificativo depende en buena medida de la recepción, la lectura o la interpretación que se haga de ella; o sea, que lo antropológico reside también en el ojo del espectador. Idealmente, el documental etnográfico no debe ser la mera ilustración de una tesis antropológica que ya se da por hecho, 
sino que, al igual que el trabajo de campo, debe ser en sí mismo un proceso de descubrimiento, en el que podamos saber dónde comienza pero no adónde nos llevará ni cómo terminará. Así, comprenderemos el cine etnográfico como aquel que propicia un diálogo intercultural, que provoca una experiencia etnográfica, una interacción o transacción en la que ambas partes resultan transformadas.

Para explicar mejor nuestra concepción de experiencia etnográfica y de cine etnográfico conviene desmenuzar la categoría y analizar sus términos por separado. La palabra "cine" normalmente se refiere a imágenes en movimiento. El término en inglés movies viene precisamente de moving images; sin embargo, estas imágenes, en sentido estricto, no se mueven; se trata de series de fotogramas fijos que, proyectados a 24 cuadros por segundo, producen en el ojo humano la ilusión de movimiento. Este fenómeno óptico es conocido como "persistencia retiniana": nuestra retina conserva una impresión visual por más tiempo del que de hecho dura, esta se queda grabada por un instante extra antes de desaparecer, y nuestro cerebro se encarga de enlazarla y generar una continuidad con la imagen que le sigue. En realidad, las imágenes no se mueven por sí solas, sino que nosotros las animamos y solo adquieren movimiento al ser vistas por un espectador. Por lo que consideramos que el cine es, primordialmente, una forma de experiencia humana, un fenómeno estético y cognitivo más allá de un lenguaje, una tecnología, una disciplina artística o una industria. Podemos afirmar que hay cine cuando se da una interacción entre determinada secuencia de imágenes y un sujeto dispuesto a navegar a través de ellas.

Por otro lado, más que únicamente imágenes que se mueven, el cine se trata de imágenes que nos mueven, nos conmueven, nos hacen pensar $y$ sentir, $y$ a veces también nos impulsan a actuar. Desde nuestro punto de vista, el término moving images puede tener tres distintas lecturas: imágenes en movimiento, imágenes conmovedoras e imágenes motrices. Las imágenes cinéticas nos dicen cosas, pero no solo comunican información, sino que generan emociones, provocan empatía, nos transportan a lugares y trastocan el tiempo. Sin importar el formato, el género o el soporte - sea corto, medio o largometraje; película de 8, I6 o 35 milímetros, video analógico o digital; animación, documental o ficción; drama, comedia, acción, misterio o terror-, cuando estamos ante imágenes significativas, que de alguna manera nos impactan y nos transforman, entonces podemos decir: "esto es cine".

Ahora bien, la noción de "etnografía" suele definirse de dos maneras distintas. Primero, como la metodología por excelencia para llevar a cabo una investigación antropológica, como el conjunto de técnicas y procedimientos que definen el trabajo de campo. También es común el uso del término para referirse a los resultados de dichas investigaciones, como la descripción más o menos integral de una cultura 
o de un grupo social: una etnografía de los huicholes, por ejemplo, se refiere a un estudio que abarca diferentes aspectos que conforman la vida social y la reproducción cultural de ese pueblo.

Sin menospreciar ni contradecir ninguna de estas dos acepciones, quisiera proponer otra manera de entender la etnografía, acaso más esencial o filosófica. Nos parece más adecuado caracterizarla antes que nada como una forma de experiencia, una disposición, una actitud, una forma de mirar. Un tipo de sensibilidad que implica un constante extrañamiento, asombro, curiosidad e interés ante la constatación de la identidad, la alteridad y la diversidad cultural. Entendida de ese modo, la experiencia etnográfica - desligada de una cuestión metodológica, anterior a la labor descriptiva y la reflexión crítica, desvinculada de un producto escrito- no es exclusiva de los antropólogos; es cierto que estos la suscitan, la cultivan y la analizan, pero en el fondo este tipo de vivencia tiene cierto carácter universal. No es necesario estudiar una carrera, ni viajar a comunidades remotas para encontrarse con los "otros" exóticos; la experiencia etnográfica puede suscitarse a la vuelta de la esquina, ante nuestros propios vecinos, o incluso hacia nosotros mismos.

\section{Observación, participación, escucha y diálogo}

Quizá la mejor manera de identificar el carácter etnográfico de un filme sea revisando si comparte algunos principios metodológicos básicos de la práctica etnográfica, si es afín con el espíritu, las técnicas y los procedimientos de la investigación de campo establecidos desde tiempos de Bronislaw Malinowski. Dentro de dichos preceptos, sin duda, la observación es un componente indispensable del trabajo antropológico, es la vía más importante para adentrarnos y entender otros mundos, además de que constituye el vínculo entre la experiencia etnográfica y la creación audiovisual. La mirada y la imaginación son determinantes para la antropología, tanto como para el cine y la fotografía; en estas disciplinas el buen observador debe cultivar la mirada, dirigirla, enfocarla y afinarla para recorrer desde el paisaje y el panorama general hasta el detalle etnográfico más sutil y los pequeños gestos aparentemente insignificantes de la cultura y la vida cotidiana.

Existe una corriente llamada cine observacional que tiene profundas raíces en la historia del cine documental, pero se consolidó sobre todo en los años sesenta,

I Ahondar en la historia del cine observacional nos desviaría del tema central de este ensayo, nos obligaría a realizar un largo recorrido por el cine documental británico, a partir del llamado free 
aprovechando las nuevas tecnologías de la época (cámaras más ligeras, portátiles, silenciosas, que rodaban por más tiempo y, sobre todo, la posibilidad de grabar el sonido de manera sincronizada junto con la imagen), para captar la realidad de tal manera que al ver la película el espectador tuviera la sensación de estar abí, como un observador dentro de la escena. El cine observacional pretende ofrecer rebanadas de la realidad con la menor intermediación posible (Grimshaw y Ravetz, 2009:23). Sin duda, la premisa del cine observacional resulta muy prometedora; no obstante, en su afán por mantener la observación lo más pura posible y no interferir en la situación que se filmaba, algunos autores se abstenían por completo de involucrarse, no interactuaban, buscaban desaparecer detrás de la cámara, pasar inadvertidos, volverse tan invisibles como una mosca en la pared. Así, renuentes a dar el paso hacia la observación participante, se cerraban al contacto y al verdadero encuentro con la alteridad.

Resulta interesante preguntarnos si este cine al estilo mosca en la pared puede considerarse plenamente etnográfico. Quizás lo sea en la medida en que trata a otras culturas o sociedades; no obstante, carece de los elementos participativos o colaborativos que, como veremos más adelante, predominan en el panorama del cine etnográfico actual. En otras palabras, este caso permite reconocer que puede haber, y de hecho ha habido por mucho tiempo, una clase de cine con valor etnográfico que se contentaba con observar sin tomar en cuenta la reciprocidad de la mirada.

En contraste, pero fundamentado en la misma revolución tecnológica, el cinéma vérité del francés Jean Rouch (2003:I4I, 220) planteaba que no basta con observar. Según su concepción el cine etnográfico debe ser participativo e interactivo. El documentalista no puede no ser parte de lo que documenta; resulta absurdo ocultar su presencia; no debe contentarse con mirar desde lejos o desde fuera; debe asumir su papel como un actor más y ser consciente del inevitable impacto de su presencia. Más aún, el sentido participativo también puede implicar compartir la mirada con los otros, darles acceso y hacerlos partícipes de la investigación o la producción del filme, como veremos más adelante.

Otro elemento constitutivo del cine etnográfico es su incuestionable valor testimonial, su carácter de repositorio de la palabra y de la memoria de la humanidad. El énfasis en la observación durante el trabajo de campo muchas veces provoca que se olvide la importancia de la escucha en la etnografía, así como, en el lenguaje

cinema, y su posterior evolución en el cine directo estadounidense de los años sesenta. Pero para el lector interesado en esta corriente se recomienda la lectura de dos artículos clave para comprender el cine observacional: "Observational Cinema" de Colin Young y "Beyond Observational Cinema" de David MacDougall, ambos incluidos en Principles of Visual Anthropology (Hockings, 1975). 
audiovisual, el peso de la imagen ha relegado la dimensión sonora a un segundo plano. La escucha es un componente decisivo de la experiencia etnográfica, así como la grabación de audio y el diseño sonoro lo son para la creación documental. En el cine etnográfico no solo se trata de saber ver sino también de saber escuchar las palabras y las voces de los otros en su propia lengua, con sus acentos, tonos, matices e inflexiones. Por esto, desde la perspectiva etnográfica resulta importante reivindicar el uso del término "antropología audiovisual", contemplando la experiencia etnográfica en su mayor complejidad.

Pero al igual que no basta con observar sin participar, tampoco basta con escuchar a los otros, es primordial conversar con ellos. Jean Rouch (2003:18,19) hablaba de un cine dialógico, en el que los sujetos ya no son informantes sino interlocutores, con quienes podemos establecer una conversación e incorporar sus puntos de vista en el filme. La conversación se puede dar entre los personajes del documental y el realizador, entre los mismos sujetos que aparecen en la cinta, o entre todos ellos y el público que verá la película. Se trata, en última instancia, de escuchar y hacer escuchar todas las voces, amplificarlas y difundirlas, generar debates, abrir nuevos canales que faciliten la comunicación entre comunidades y culturas, entre sectores de la sociedad que de otra manera permanecerían incomunicados. De hecho, de acuerdo con la propuesta de Jean Rouch, el cine-etnógrafo debe asumir un papel más activo, puede ir más allá de la interacción espontánea y llegar incluso a la provocación, a detonar, suscitar encuentros, generar reacciones, confrontar a la realidad, cuestionar al mundo (Henley, 2009:255-277).

\section{Documental colaborativo}

Más allá de los principios recién expuestos —observación, participación, escucha y diálogo-, en los últimos años el cine etnográfico ha seguido experimentando y reinventándose, sobre todo por la vía de la colaboración. En sintonía con las nuevas corrientes del pensamiento antropológico, en las tendencias recientes del cine etnográfico han surgido cada vez más películas que ya no son hechas únicamente desde la perspectiva de los antropólogos/documentalistas, sino que incorporan de muy distintas maneras las voces, las ideas y las perspectivas de los otros, comparten con ellos la mirada y la autoría como co-realizadores.

Estas estrategias colaborativas han recibido distintos nombres, dependiendo del contexto y de sus características particulares: cine o video indígena, comunitario, participativo, o se les ha llamado transferencia, capacitación o apropiación de medios, 
prácticas de autorrepresentación o producción audiovisual compartida. Documental colaborativo no es un nombre formalmente establecido y en nuestra opinión tampoco es muy afortunado; sin embargo, nos parece adecuado porque destaca precisamente el aspecto que define este tipo de cine documental.

En este punto es conveniente especificar desde qué perspectiva teórica se ha construido la categoría de documental colaborativo, de qué campos proviene y en cuáles otros se disemina. En este artículo entendemos el documental colaborativo como una forma de etnografía experimental o una metodología alternativa para la investigación antropológica, muy propicia para explorar nuevas realidades sociales y culturas en transformación. Pero resulta fundamental reconocer que las estrategias colaborativas forman parte de un paradigma más amplio de producción del conocimiento, y que también se han desarrollado desde otras disciplinas más allá de la producción de cine etnográfico, por ejemplo, en las artes visuales, el teatro, la literatura, el periodismo, por mencionar algunas.

El parentesco entre la antropología y el documental colaborativo resulta ambiguo y un tanto problemático. Por una parte, podemos argumentar que las estrategias participativas y colaborativas buscan emancipar al documental de una tradición y una lógica de investigación de raíz colonial, como es el método etnográfico. Ciertamente, el documental colaborativo puede entenderse como un intento por romper con las formas y los estilos de representación audiovisual del cine etnográfico clásico, sustentado en posturas éticas y epistemológicas radicalmente distintas. No obstante, es imposible negar que las estrategias participativas y colaborativas tienen profundas raíces en la experiencia etnográfica, e igualmente podría afirmarse que el documental colaborativo surge como un intento desde dentro del cine etnográfico por reinventarse a sí mismo.

De hecho, en los últimos años hablar de metodologías participativas en el terreno de la antropología se ha convertido en una tendencia muy marcada, casi una moda académica. Sin embargo, sobre todo en la antropología latinoamericana, las numerosas reflexiones han permanecido aisladas y aún no han sido sistematizadas en una discusión teórica ni metodológica integral y coherente. Por ello, para caracterizar y analizar el documental colaborativo, optamos por reflexionar en primer lugar en torno a la propia experiencia en este tipo de producción, luego por explorar las bases filosóficas sobre las que se construye - pero que a la vez trastoca y desestabiliza-, además de reconstruir a grandes trazos su genealogía, desde sus orígenes hasta nuestros días, aterrizándola particularmente en nuestras latitudes.

Para empezar, es posible identificar diferentes formas y modalidades de colaboración. Esta suele referirse a la relación entre el antropólogo-documentalista y 
los sujetos-personajes, pero puede darse igualmente entre diferentes personajes delante y/o detrás de la cámara; el tipo más básico radica en la aceptación de los sujetos para ser grabados y brindar su testimonio, para convertirse en personajes de un documental. También puede suceder que las distintas comunidades tomen las cámaras por iniciativa propia o a través de un proceso de transferencia de medios, o se involucren en la elaboración del guion, o participen en recreaciones y dramatizaciones, como actores que se representan a sí mismos, o que con su voz y sus testimonios formen la pista sonora en la posproducción, o bien como parte de la cadena de promoción, difusión y distribución del filme.

Pero también es posible entender la colaboración como la integración de equipos multidisciplinarios en el proceso creativo y de investigación. La noción de colaboración también comprende, a nuestro entender, una forma distinta de organizar el trabajo de realización, una estructura más flexible y horizontal que rompe con las jerarquías rígidas de la producción cinematográfica. Por último, podemos pensar en la colaboración en términos de la manera particular que tiene este cine de dirigirse al público; en el cine colaborativo suele destinarse un papel más activo al espectador, dejándole la libertad de sacar sus propias conclusiones, de jugar un papel más activo en la interpretación del sentido de la obra que aprecia. Se trata por lo general de un documental más interactivo, abierto y polisémico.

Las diversas experiencias de producción audiovisual compartida han obligado a la antropología visual a plantearse algunas preguntas fundamentales acerca de las cualidades de la imagen y su traducibilidad para la comunicación intercultural. ¿ En qué medida la imagen constituye un lenguaje universal que la gente de cualquier parte del mundo puede comprender y reproducir? ¿Qué tan cierto es que cada cultura tiene su propia forma de ver y representar el mundo? Por otra parte, si cada pueblo, grupo o comunidad es capaz de autorrepresentarse, entonces ¿para qué sirve el antropólogo-documentalista, cuando las comunidades son capaces de producir sus propios relatos y de comunicarse efectivamente con otras semejantes? Para empezar, no se trata de que cada quien produzca y reproduzca sus propios discursos, sino de entablar conversaciones genuinas, despertar empatía y compartir la mirada. La riqueza del conocimiento antropológico está precisamente en los cruces de diversas lógicas culturales, en la conversación, en la colaboración, en la construcción colectiva del conocimiento. En este sentido, el rol del antropólogo-documentalista ya no es el de una autoridad que se coloca por encima de los demás, que explica una cultura y prescribe soluciones a los problemas sociales; más bien asume un papel aparentemente más modesto y humilde; sin embargo, muy noble y nada desdeñable. Se convierte en un intermediario, un intérprete que facilita la comunicación entre dos 
mundos. Desde esta perspectiva colaborativa, cumple la función de gestor, promotor o facilitador; sirve de enlace, de mediador, y en ocasiones incluso incitador de la acción colectiva.

Un aspecto distintivo del documental colaborativo es su carácter de práctica colectiva, de acción concertada que genera sinergia y reciprocidad, que refuerza los lazos comunitarios y regenera el tejido social. Lejos de las pretensiones artísticas autocomplacientes del cine de autor, cumple una función casi ritual, se trata de una experiencia colectiva, un "performance" social, un fenómeno compartido que produce comunión y complicidad entre los personajes, los realizadores y el público. La colaboración puede adoptar muchas y distintas modalidades, y actuar en diferentes niveles. Pero en todos los casos contribuye a romper la asimetría y neutraliza la carga colonialista inherente a la antropología y al cine etnográfico clásico. El cine colaborativo permite reconfigurar los juegos de poder y genera un verdadero conocimiento compartido, al tejer redes de manera más horizontal entre todas las partes involucradas.

El documental colaborativo encierra una gran promesa de sinergia entre el cine y la antropología; es un tipo de producción audiovisual completamente coherente con la metodología etnográfica y afín con la perspectiva intercultural que define la labor antropológica contemporánea. Coincide con las tendencias actuales del pensamiento antropológico, como la teoría del actor-red, tal como la plantea Bruno Latour (2009); la teoría de la reflexividad, como la postulan Pierre Bourdieu y Loïc Wacquant (1995); así como la antropología interpretativa y dialógica de Clifford Geertz (1992). Se constituye además como una vertiente de la antropología aplicada, sensible y comprometida.

\section{Dimensiones trastocadas}

Más allá del ámbito de la antropología, el documental colaborativo plantea un desafío crítico para las ciencias sociales y las humanidades en general, ya que atraviesa y desestabiliza los fundamentos epistemológicos, éticos, estéticos y políticos de los enfoques dominantes en la teoría social y los estudios culturales. Comentemos brevemente cada una de estas cuatro dimensiones.

En cuanto a la dimensión epistemológica, las estrategias colaborativas de realización liberan al documental de la pretensión de objetividad del documental clásico y de la antropología positivista; parten siempre de la subjetividad, nos colocan en el terreno de la intersubjetividad y la interculturalidad. La imagen deja de ser un reflejo 
del mundo y se transforma en refracción, distorsionada, localizada y condicionada por una serie de situaciones materiales, sociales y culturales. La pantalla funciona a la vez como una ventana y como un espejo, dice el cineasta Alan Berliner; como una ventana para adentrarnos en otros mundos y comprender la perspectiva de los otros, pero que a la vez permite que nos observemos unos a otros y a nosotros mismos. El cine colaborativo se construye precisamente en el encuentro de miradas; de él emana un conocimiento que se fundamenta en el encuentro de distintas perspectivas, trastocando las nociones de autoridad y autoría. Además, aquí el espectador tiene un papel más activo en la interpretación, no es pasivo; ante la polifonía y la polisemia, se convierte en un interlocutor más, a quien se interpela y se exige sacar sus propias conclusiones.

La dimensión estética en el documental colaborativo va más allá del valor poético que pueda tener un producto audiovisual; trasciende su posible belleza como obra de arte. Además de la gran carga sensorial que transmiten la imagen y el sonido, el documental colaborativo parece indicar que el diálogo intercultural, la intención o la disposición para conocer a diferentes grupos sociales es en sí una experiencia estética. Lo estético en la antropología se halla en la experiencia primordial del encuentro con el otro, en el desdoblamiento del yo para intentar adoptar y comprender perspectivas distintas. En el documental colaborativo, donde el encuentro con la alteridad sucede de manera radical y en diferentes niveles, podemos hablar de una estética del extrañamiento, del asombro y la curiosidad ante lo diferente, en el plano más profundamente humano.

En el documental colaborativo la cuestión ética es un componente determinante; se refiere, a grandes rasgos, a la relación que se establece entre el documentalista, los personajes y los espectadores. Se expresa casi siempre en forma de dilemas y encrucijadas ante los cuales no hay una única manera correcta de actuar. En este sentido, para analizar la postura ética de un documental no basta con ver la película terminada, es necesario mirar todo el proceso de aproximación e interacción con los sujetos. De entrada, no se asume la iniciativa de hablar de ni por el otro, sino con el otro, de escucharlo antes que nada; no se trata de estudiar a, sino de aprender de, y de crear junto con los otros. Esto forma parte de una actitud humilde, respetuosa, una mirada horizontal, de frente, de igual a igual, que parte del reconocimiento de que los demás nunca deben ser considerados como medios para nuestros fines, sino siempre como fines en sí mismos.

La imagen es un arma de varios filos, susceptible de ser utilizada como instrumento político, ya sea para la dominación o la liberación, como herramienta de sometimiento y control, o para fomentar el pensamiento crítico y la transformación 
social. Lo que escogemos representar, la forma en que lo representamos, para qué lo representamos y qué hacemos con esa representación, conlleva inevitablemente una carga política. Mucho se ha hablado de la carga colonialista con la que nació la antropología y de cómo el cine etnográfico no ha conseguido deshacerse completamente de esa herencia. A nuestro parecer, el documental colaborativo brinda la posibilidad de romper la asimetría de la representación, invierte o neutraliza los juegos de poder involucrados en la creación de imágenes. El hecho de ceder, compartir los medios con los otros, provocar procesos de autorrepresentación y retroalimentación intercultural, normalmente implica una postura política solidaria, cómplice, comprometida con los derechos humanos y la libertad de expresión, que busca tener cierta incidencia en la realidad, y que le imprime a la antropología visual el carácter de antropología aplicada.

\section{Precursores y panorama actual}

A continuación haremos un breve recuento de los autores, escuelas y corrientes que han marcado el desarrollo del documental colaborativo. Las primeras experiencias se remontan a 1914, cuando Edward S. Curtis, fotógrafo y viajero estadounidense, dedicado por mucho tiempo a documentar la vida de las tribus de indios nativos norteamericanos, dio a conocer la película In the Land of the Head Hunters (1914). Para la realización de dicho filme, durante tres años contó con la colaboración de miembros de la comunidad kwakiutl; estos no solo actuaron para la película, también participaron en la elaboración de la escenografía, las máscaras, los vestuarios, además de recrear para la cámara las danzas ancestrales, que ya en aquel entonces estaban cayendo en desuso. Asimismo, al lado de Curtis participó activamente el indio George Hunt, quien fuera informante clave de Franz Boas y Ruth Benedict en investigaciones precedentes. A pesar de la relevancia del proyecto, este episodio ha sido prácticamente olvidado por la historia oficial del cine documental (Cousins y Macdonald, 2006: 2I).

Años más tarde, tras conocer la obra de Edward S. Curtis, el explorador Robert Flaherty decidió hacer algo similar con los inuits, a quienes conocía gracias a su trabajo como geógrafo y cartógrafo. Él y su amigo aborigen, cuyo nombre real no era Nanook, planearon en conjunto la filmación de varias escenas que aparecen en el revolucionario filme Nanook of the North (1922). Flaherty revelaba la película in situ y juntos analizaban las imágenes filmadas; en este proceso, Nanook proponía otros elementos y nuevas escenas para los siguientes días. Esta labor conjunta dio 
origen al primer documental narrativo de la historia y a la primera obra maestra del cine colaborativo.

Es importante mencionar que estas experiencias pioneras poseen múltiples matices y sutilezas, aspectos problemáticos y complejidades que un bosquejo apresurado como este se ve obligado a obviar. Las relaciones de trabajo entre Edward S. Curtis y sus colaboradores kwakiutl, entre ellos George Hunt, así como entre Robert Flaherty y Nanook, no fueron tan simples y armoniosas como suele presentarse. Algunos autores, como Gidley (2003), Hausman y Kapoun (2009), Lawlor (1994) y Lowry (1994) abordan el caso de Edward S. Curtis, mientras que autoras como Rony (1996) analizan de manera crítica los productos cinematográficos de Robert Flaherty, sobre todo en términos éticos. Para los fines de este ensayo, basta con señalar a Curtis y Flaherty como los grandes precursores y señalar la necesidad de analizar más a profundidad cada caso.

Varias décadas después, en los años sesenta, el fotógrafo Sol Worth también decidió experimentar con la cámara y la cedió a un grupo de indios navajo. Así es como surgió el proyecto Through Navajo Eyes, que comprendió una serie de documentales filmados por los propios indios, acompañados por un libro que reflexiona sobre dicha experiencia, escrito en coautoría con el antropólogo John Adair (Chalfen, 2007:165).

Mientras tanto, en el desierto del Kalahari, en África, el antropólogo y cineasta estadounidense John Marshall — después de filmar por casi 50 años a una familia de pastores nómadas bosquimanos !Kung y ju/'hoansi- decidió dejar a un lado su cámara para coger la pala, cavar pozos de agua y defender junto con ellos sus territorios ancestrales de caza y recolección. Sin dejar de lado su ímpetu documentalista, Marshall contrató a un equipo que filmó la lucha por las tierras y los derechos de los pueblos de la región. Este es un caso de cine colaborativo entendido como una vía para el activismo, un cine al servicio de las necesidades y los intereses de los personajes, un caso ejemplar y paradigmático de lo que proponemos llamar antropología visual aplicada (Zirión y Vega, 20I2:8).

Ciertamente, los primeros casos de cine colaborativo provienen sobre todo de Norteamérica, quizá por ser una región que siempre se ha mantenido a la vanguardia tecnológica, pero posteriormente su evolución ha sido mayor o más interesante en otras áreas del mundo. En Francia, desde luego, tuvo un desarrollo decisivo gracias al trabajo antes mencionado de Jean Rouch; películas como Jaguar (1957), Yo, un negro (1958), Crónica de un verano (1960) y La caza del león con arco (1967) representan diferentes formas de colaboración entre el autor, los personajes y el público.

Pero también hay que destacar cintas de corte indígena producidas en América Latina, principalmente dentro de la corriente del llamado Tercer Cine Latinoame- 
ricano (Getino y Solanas, 1988 [1969]); trabajos de cine indígena en Bolivia, por Jorge Sanjinés, o los correspondientes en Colombia, a cargo de la documentalista Marta Rodríguez (Paranaguá, 2003). Un caso singular y extraordinario es el cine etnobiográfico de Jorge Prelorán (2006:29-3I), en Argentina, que sigue un método muy preciso y singular basado en la complicidad con sus personajes para transmitir de forma magistral su voz y su alma. Más recientemente sobresale el proyecto Video Nas Aldeias, fundado por Vincent Carelli, con indígenas en el Amazonas brasileño; dicho proyecto es, sin duda, un parteaguas en las experiencias de producción colaborativa dentro del cine documental latinoamericano (Bernadet et al., 2004:8-II). Al norte del continente, en Canadá, también encontramos experiencias de colectivos y proyectos como Wapikoni Mobile e Igloolik Isuma Productions, con espléndidos resultados, como la película Atanarjuat the Fast Runner de Zacharias Kunuk y Norman Cohn (Steven, 1993).

En México, el desarrollo del documental colaborativo está íntimamente ligado al proyecto de Transferencia de Medios Audiovisuales a Organizaciones y Comunidades Indígenas (TMA), puesto en marcha en 1989 por el Instituto Nacional Indigenista (INI). Esta iniciativa surgió de un grupo de creadores mexicanos que entraron en contacto con los Talleres Varan, un proyecto para la capacitación de cineastas del "tercer mundo" en el que estuvo involucrado Jean Rouch (Vázquez Mantecón, 2012:270). Posterior a esta experiencia algunos de estos cineastas, a través del Archivo Etnográfico Audiovisual del INI, pusieron en marcha talleres de cine y montaron Centros de Video Indígena en varios estados, como Yucatán, Oaxaca y Michoacán. Dichos Centros tenían el objetivo de poner los medios audiovisuales al alcance de las comunidades y los pueblos indígenas, para darles la posibilidad de escribir ellos mismos su historia y generar su propia memoria visual. El primer taller piloto fue impartido en 1987 con mujeres tejedoras de San Mateo del Mar, Oaxaca; este dio como resultado las películas Tejiendo Mar y Viento de Luis Lupone y La vida de una familia ikoods de la indígena huave Teófila Palafox (Zamorano y Wammack, 20I4:I29-I4I).

Dichas experiencias, impulsadas desde el Estado mexicano en un principio, fueron truncadas al poco tiempo, no se les dio seguimiento y no tuvieron continuidad. Sin embargo, dejarían semillas que años después darían frutos en el ámbito independiente. Es así como surgieron colectivos y medios comunitarios como Ojo de Agua Comunicación y TVTámix, en Oaxaca; en Chiapas son destacables las experiencias del Chiapas Media Project y del Proyecto Videoastas Indígenas de la Frontera Sur (Köhler et al., 20Io). También hay que destacar la labor realizada durante los últimos años por nuevas iniciativas como el Campamento Audiovisual 
Itinerante (CAI), un proyecto formativo para cineastas independientes del interior de la república, o Ambulante Más Allá, proyecto para la capacitación en la producción documental a jóvenes indígenas del sureste del país (Zamorano y Wammak, 2014:I42-I47).

En el ámbito urbano, en los años ochenta, con la ola de cineastas independientes conocidos como superocheros, surgieron los primeros experimentos de colaboración entre cineastas como Luis Lupone y Rafael Rebollar, y ciertos personajes urbanos populares, como el boxeador y candidato a diputado Rubén "Púas" Olivares, protagonista del documental Gancho al hígado (1982), o el famoso bailarín de Tepito conocido como El Tirantes (1983). También en los ochenta algunos artistas visuales se acercaron a trabajar con tribus urbanas en la periferia de la ciudad, chavos banda y punks de Neza, y el resultado fueron filmes como Nadie es inocente de Sarah Minter y Sábado de mierda de Gregorio Rocha (Vázquez Mantecón, 2012:293).

En esta genealogía de documental urbano mexicano se inscribe mi propia experiencia como documentalista desde hace más de io años. En conjunto con los otros miembros del colectivo Homovidens, Adrián Arce y Diego Rivera, hemos realizado diferentes propuestas audiovisuales aplicando diversas estrategias colaborativas en el proceso de conocer y construir puentes de comunicación con jóvenes marginales y grupos subalternos de la Ciudad de México: niños de la calle, jóvenes en barrios bajos, albañiles y adolescentes en reclusión. Entre estos trabajos se encuentran: Chido mi banda, chido mi barrio (2002), resultado de un ejercicio de transferencia de medios audiovisuales con jóvenes en situación de calle en el barrio de La Soledad, en el centro de la Ciudad de México; Voces de la Guerrero (2004), que presenta los resultados y experiencias de un taller de foto y video impartido a un grupo de chavos callejeros de la colonia Guerrero (Ayala Blanco, 2006:32I); Microhistorias urbanas (2010), serie de tres cortometrajes realizados por jóvenes de entre I4 y 17 años del barrio de Tlatelolco, como parte de un taller de documental multimedia basado en ciertos principios del cine etnobiográfico de Jorge Prelorán (2006); y Fuera de foco (2013), documental colaborativo con adolescentes internos en la cárcel para menores de San Fernando, al sur de la Ciudad de México, como resultado de diversos talleres de video y arte impartidos en dicha institución. En estos proyectos la reflexión y la experimentación han ido de la mano, teoría y práctica se han ido complementando y retroalimentando.

Es relevante también rescatar la importancia de la labor documental realizada en los últimos años, particularmente en la ciudad de Tijuana, laboratorio urbano en la frontera norte del país. El auge de la cultura audiovisual que ha vivido recientemente esta región ha brindado al documentalismo mexicano importantes trabajos colaborativos que dan voz al subalterno, como Que suene la calle (2006) o El hogar al 
revés (2014), de Itzel Martínez del Cañizo o Félix, autoficciones de un traficante (20II), de Adriana Trujillo (Trujillo, 2013; Cordero, 2013).Todos estos trabajos forman parte de una nueva ola de video urbano colaborativo que ha sabido aprovechar las tecnologías digitales, bajo las premisas teórico-metodológicas del cine colaborativo.

La historia trazada demuestra que las estrategias de colaboración en la producción documental no son de reciente creación, sino que tienen hondas raíces en la tradición del cine, los medios audiovisuales y la etnografía en México y el mundo. Hay varios autores pioneros, obras clásicas y experiencias muy significativas, aciertos y equivocaciones de las que sin duda tenemos mucho que aprender. Pero también es cierto que lo que ha sucedido en las últimas dos décadas en el campo del consumo y la circulación audiovisual no tiene precedentes.

\section{Desenlaces y nuevas complicidades}

En el recuento anterior revisamos diferentes experiencias de colaboración para la producción audiovisual, pero también es importante preguntarnos por las formas de difusión, circulación y consumo de este tipo de documentales y otros géneros marginales. En este sentido, cabe señalar que en los últimos diez años se han inaugurado varias iniciativas culturales, festivales, cineclubes y programas académicos que buscan exhibir, promover o estudiar el cine independiente en general. Para mencionar solo algunos proyectos que han resultado trascendentes: el Encuentro Hispanoamericano de Video Documental Independiente "Contra el Silencio Todas las Voces", las Muestras de Cine y Video Etnográfico y Testimonial organizadas por el ciesas-Golfo, los diversos Foros de Cine y Video Indígena y Comunitario, las Jornadas de Antropología Visual que iniciaron en la ENAH, así como festivales especializados en cine documental, como el Festival de la Memoria, Ambulante y DocsDF, entre otros. A la existencia desde hace más o menos una década de varios laboratorios de medios audiovisuales e investigación social dentro de diferentes instituciones académicas (como el Laboratorio de Antropología Visual de la UAM-I, el Laboratorio Audiovisual de Investigación Social del Instituto Mora, el Laboratorio Audiovisual del ciesas y el Departamento de Medios Audiovisuales de la ENAH), se suma la reciente creación de otros espacios académicos que promueven la producción y la investigación en este campo (como el Seminario permanente de Antropología Visual en el Instituto de Investigaciones Antropológicas de la UnAM, el Laboratorio Multimedia en la Facultad de Ciencias Políticas y Sociales, el Laboratorio de Medios Audiovisuales de la UACM, el Seminario de Cine Etnográfico que operó durante tres 
años en el Instituto de Investigaciones Estéticas), iniciativas que recientemente se han organizado para fundar la Red Mexicana de Antropología Visual.

Por otra parte, no podemos ignorar el profundo impacto que han tenido las nuevas tecnologías digitales en los modos de circulación, socialización y consumo de materiales audiovisuales a nivel global. Internet ha generado una verdadera revolución en términos de la difusión de contenidos audiovisuales; una imagen puede ser vista por millones y darle la vuelta al mundo en cuestión de segundos; la distancia entre productores y consumidores de imágenes se ha borrado. Las nuevas tecnologías de la imagen y la cultura digital, cada vez más accesibles para más gente, también han facilitado y potenciado el proceso de transferencia y apropiación de medios audiovisuales entre diferentes comunidades y grupos sociales. A partir de esto, en los últimos años han proliferado diversas iniciativas locales de producción audiovisual con rasgos e identidad propios, casi siempre ajenos a la antropología académica; estas producciones brindan la posibilidad de ver y escuchar a quienes han permanecido en silencio o invisibles, nos acercan a vidas que estaban en el anonimato o que solo habían sido vistas a través de una lente externa. Este escenario de alguna manera nos obliga a repensar las relaciones entre la antropología y la imagen, y nos conduce a cuestionarnos sobre las nuevas formas y sentidos que está cobrando el cine etnográfico contemporáneo, en la llamada era de la convergencia digital.

Las estrategias colaborativas de producción audiovisual constituyen un espacio de posibilidades, de encuentros y desencuentros interculturales. Estas nuevas $-y$ no tan nuevas - aproximaciones participativas marcan un hito en la construcción de la alteridad, que deja de tener una carga política tan asimétrica y vuelve al reconocimiento básico de múltiples y diferentes identidades. La colaboración en la investigación etnográfica y en la producción de cine documental representa un terreno fértil para la libre expresión, abre nuevos horizontes para la creatividad y el conocimiento, promueve el ejercicio de la memoria y la imaginación colectiva, ofrece una vía alternativa para la comunicación y la comprensión entre culturas. Al mismo tiempo, este paradigma emergente nos permite restituir a la imagen su agencia, más allá de su valor representacional; las imágenes poseen la capacidad de generar efectos palpables en la realidad, tienen un peso tangible dentro de las redes y las cadenas de acción y transformación social. Esta es, en última instancia, la convicción que le da sentido al planteamiento de una antropología visual aplicada. ${ }^{2}$

2 Agradezco mucho a los dictaminadores anónimos cuyas agudas observaciones contribuyeron a enriquecer significativamente este artículo, así como a Valeria Cuevas por su invaluable ayuda para sistematizar la información que lo integra. 


\section{Bibliografía}

Ayala Blanco, Jorge (2006), La herética del cine mexicano, Océano, México.

Bernardet, Jean-Claude et al. (2004), Mostra Video Nas Aldeias: Um olhar indigena. Video in the villages exhibition: Trough indian eyes, Centro Cultural Banco do Brasil/norad/Ministério da Cultura, Brasil.

Bourdieu, Pierre y Loïc Wacquant (1995), Respuestas. Por una antropología reflexiva, Grijalbo, México.

Chalfen, Richard (2007),"The Worth/Adair Navajo Experiment-Unanticipated Results and Reactions", en B. Engelbrecht (ed.), Memories of the Origins of the Ethnographic Film, Peter Lang, Fráncfort.

Cordero, Liliana (2013), Trayectorias de la cultura audiovisual tijuanense, tesis de doctorado inédita, Instituto de Investigaciones Estéticas-Universidad Nacional Autónoma de México, México.

Cousins, Mark y Kevin Macdonald (eds.) (2006), Imagining Reality, Faber and Faber Limited, Londres.

García Canclini, Néstor (20ı), "Cuándo hay cine iberoamericano: cinéfilos, videófilos e internautas", Conferencia impartida en la Universidad de Harvard [ms. disponible en archivo electrónico].

Geertz, Clifford (1992), La interpretación de las culturas, Gedisa, Barcelona.

Getino, O.y Fernando Solanas (1988), "Hacia un Tercer Cine" [1969], Hojas de cine, vol. I., Universidad Autónoma Metropolitana/Secretaría de Educación Pública/Fundación Mexicana de Cineastas, México.

Gidley, Mick (ed.) (2003), Edward S. Curtis and the North American Indian Project in the Field, University of Nebrasaka Press, Lincoln.

Grimshaw, Anna y Amanda Ravetz (2009), Observational Cinema: Anthropo$\log y$, Film, and the Exploration of Social Life, Indiana University Press, Indiana.

Hausman, Gerald y Bob Kapoun (eds.) (2009), The image Taker: The Selected Stories and Photographs of Edwars $S$. Curtis, World Wisdom, Bloomington.

Henley, Paul (2009), The Adventure of the Real: Jean Rouch and the Craft of Ethnographic Cinema, The University of Chicago Press, Chicago.

Hockings, Paul (1975), Principles of Visual Anthropology, Mouton Publishers, Nueva York.

Jacknis, Ira (1988), "Margaret Mead and Gregory Bateson in Bali: Their Use of Photography and Film" en Cultural Anthropology, 3(2), pp. 160-I77. Recuperado de www.jstor.org/stable/656349. 
Köhler, Axel, Xochitl Leyva Solano et al. (2010), Tejiendo nuestras raíces, Centro de Artistas, Comunicadores y Antropólogos de Chiapas/Universidad de Ciencias y Artes de Chiapas/Centro de Investigaciones y Estudios Superiores en Antropología Social/unam/Xenix Film/Iwgia, México.

Krotz, Esteban (1994), "Alteridad y pregunta antropológica” en Alteridades, 4(8), Pp. 5-II.

Latour, Bruno (2009), Reensamblar lo social, Una introducción a la teoría del actor-red, Manantial, Buenos Aires.

Lawlor, Laurie (1994), The Life and Work of Edward S. Curtis, Walker, Nueva York.

Lowry, Shannon (1994), Natives of the farNorth. Alaska's Vanishing Culture Trough the Eye of Edward Sheriff Curtis, Stackpole Books, Mechanicsburg. MacDougall, David (1975), "Beyond Observational Cinema”, en P. Hockings, Principles of Visual Anthropology, Mounton Publishers, Nueva York.

Paranaguá, Paulo A. (ed.) (2003), Cine documental en América Latina, Cátedra, Madrid.

Prelorán, Jorge (2006), El cine etnobiográfico, Ediciones Universidad del Cine, Argentina.

Rony, Fatimah Tobing (1996), The Third Eye: Race, Cinema, and Ethnographic Spectacle, Duke, Durham, Carolina del Norte.

Rouch, Jean (2003), Ciné-Ethnography, ed. y trad. S. Feld, Minnesota University Press.

Steven, Peter (1993), Brink of reality: New Canadian Documentary Film and Video, Between the Lines, Toronto.

Trujillo, Adriana (ed.) (2013), Bordocs y Fronteras: cine documental en el norte de México, Bordocs-Abismos, Tijuana.

Vázquez Mantecón, Álvaro (2012), El cine súper 8 en México. 1970-1989, Filmoteca unAm, México.

Young, Colin (1975), “Observational Cinema”, en P. Hockings, Principles of Visual Anthropology, Mounton Publishers, Nueva York.

Zamorano, Gabriela y Brit Wammack (2014),"El audiovisual indígena en México y sus aportes al género documental", en C. Curiel de Icaza y A. Muñoz Hénonin (coords.), Reflexiones sobre cine mexicano contemporáneo, Cineteca Nacional, México. 
Zirión, Antonio y Valeria Vega (2012), "John Marshall. Patrimonio documental de la humanidad", John Marshall, Etnoscopio A.C/Documentary Educational Resources/Conaculta/uam, México.

\section{Filmografía}

Curtis, Edward S. (dir.) (1914), In the Land of the Head Hunters, Milestone Films, Estados Unidos [DVD].

Flaherty, Robert (dir.) (1922), Nanook of the North, Criterion Collection, Estados Unidos [DVD].

Kunuk, Zacharias (dir.) (200I), Atanarjuat the Fast Runner, Igloolik Isuma Productions, Canadá [DvD].

Lupone, Luis (dir.) (1982), Gancho al hígado, Filmoteca unAm/Trabuco, México [DVD].

(dir.) (1987), Tejiendo mar y viento, Instituto Nacional Indigenista, México [DvD].

Martínez del Cañizo, Itzel (dir.) (2006), Que suene la calle, Polen Audiovisual, México [DvD].

(dir.) (20I4), El hogar al revés, Polen Audiovisual, México [DVD].

Minter, Sarah (dir.) (1987), Nadie es inocente, Filmoteca UnAm, México [DvD]. Palafox, Teófila (dir.) (1987), La vida de una familia ikoods, INI, México [DVD]. Rebollar, Rafael (1983), El tirantes, Filmoteca unam, México [DVD].

Rocha, Gregorio (1985-1987), Sábado de mierda, Filmoteca unam, México [DvD]. Rouch, Jean (dir.) (1957), Jaguar, Argos Films, Francia [DvD].

(dir.) (1958), Yo, un negro, Argos Films, Francia [Dvd].

(dir.) (1960), Crónica de un verano, Argos Films, Francia [DvD]. (dir.) (1967), Caza de león con arco, Argos Films, Francia [DvD].

Trujillo, Adriana (dir.) (20II), Félix, autoficciones de un traficante, Polen Audiovisual, México [DvD]. (dir.) (2014), Nido de lenguas, Polen Audiovisual, México [DvD].

Zirión, Antonio y Adrián Arce (dirs.) (2010), Microbistorias urbanas, Homovidens, México [DVD]. (dirs.) (20I2), Fuera de foco, Homovidens, Etnoscopio, UAM-I, México [DVD]. 
Zirión, Antonio, Adrián Arce y Diego Rivera (dirs.) (2004), Voces de la Guerrero, Homovidens, México [DVD].

Zirión, Antonio y Diego Rivera (dirs.) (2002), Chido mi banda, chido mi barrio, Homovidens, México [DvD]. 